\title{
Demographic and comorbidity predictors of adherence to diagnostic colonoscopy in the Danish Colorectal Cancer Screening Program: a nationwide cross-sectional study
}

This article was published in the following Dove Press journal:

Clinical Epidemiology

\author{
Mette Kielsholm Thomsen' \\ Morten Rasmussen ${ }^{2}$ \\ Sisse Helle Njor ${ }^{1,3}$ \\ Ellen Margrethe Mikkelsen' \\ 'Department of Clinical Epidemiology, \\ Aarhus University Hospital, Aarhus, \\ Denmark; ${ }^{2}$ Department of Digestive \\ Diseases K, Bispebjerg Hospital, \\ Copenhagen, Denmark; ${ }^{3}$ Department \\ of Public Health Programs, Randers \\ Regional Hospital, Randers, Denmark
}

Background: Predictors of participation in colorectal cancer screening with a stool sample screening modality have been widely studied, but adherence to subsequent diagnostic colonoscopy after a positive screening test has received less attention. We aimed to determine predictors of adherence to diagnostic colonoscopy in the Danish Colorectal Cancer Screening Program. Methods: We conducted a cross-sectional study using data from National Health Service registries. We included 8,112 individuals invited to screening between March 3, 2014, and August 31,2014 , who had a positive immunochemical fecal occult blood test. Potential predictors were gender, age, region of residence, Charlson Comorbidity Index (CCI) score, specific diseases (cardiovascular disease, chronic pulmonary disease, diabetes, and cancer), and number of prior hospital stays. We estimated prevalence proportion differences (PPDs) for the associations between potential predictors and adherence.

Results: Overall, adherence to diagnostic colonoscopy was $88.6 \%$. Adherence was lower in individuals aged 75 years compared with those aged $<70$ years, PPD $=-4.20$ ( $95 \%$ confidence interval $[\mathrm{CI}]:-6.19 ;-2.20)$. Adherence decreased with a higher level of comorbidity: PPD $=-2.30$ (95\% CI: $-3.87 ;-0.74)$ for a CCI score of $1-2$ and PPD $=-9.24$ (95\% CI: -12.30 ; -6.19 ) for a CCI score of $\geq 3$ compared to 0 . For specific diseases, adherence was decreased in those with a diagnosis of cardiovascular disease, chronic pulmonary disease, or diabetes, but less for cancer. When comorbidity was measured as number of prior hospital stays, the adjusted PPDs were -2.41 (95\% CI: $-4.43 ;-0.39)$ for one to two stays and -14.50 (95\% CI: $-20.30 ;-8.74)$ for three or more stays compared with no in-hospital stays.

Conclusion: Major predictors of nonadherence to diagnostic colonoscopy after a positive immunochemical fecal occult blood test were older age, a CCI score of 1 or more, cardiovascular disease, chronic pulmonary disease, diabetes, and one or more in-hospital stays within the last year. Keywords: adherence, compliance, colorectal cancer, screening and prevention, morbidity, comorbidity

\section{Plain language summary}

Globally, colorectal cancer (CRC) is the third- and second-most common cancer in men and women, respectively. In 2014, a population-based screening program for CRC was initiated in Denmark, using fecal testing to find signs of blood as an early symptom of CRC. The program was offered free of charge to all residents aged 50-74 years. In screening, if signs of blood were found in a person's stool, he or she need to undergo further examination in the form of a colonoscopy. This will determine whether or not the person has cancer. We found that $12 \%$ of people with blood in the stool did not receive a colonoscopy within 2 months of the screening.
Correspondence: Mette Kielsholm Thomsen

Department of Clinical Epidemiology, Aarhus University Hospital, Olof Palmes Allé 43-45, 8200 Aarhus N, Denmark Tel +4587168485

Email mkthomsen@clin.au.dk 
We found that people who were older or had severe comorbidity were less likely to receive a colonoscopy. Not receiving a colonoscopy can lead to delayed treatment and poor survival in people who turn out to have cancer.

\section{Introduction}

With more than 1.3 million new cases worldwide in 2012, colorectal cancer (CRC) is the third-most common cancer in men and the second-most common in women. ${ }^{1}$ Symptoms are weak and often present at a late stage, but bleeding lesions make early detection and improved cancer specific mortality possible through identification of blood in the stool with guaiac or immunochemical fecal occult blood tests (iFOBTs). ${ }^{2-4}$ The success and effect of a FOBT screening program do not only require a high degree of participation but also adherence to the subsequent diagnostic colonoscopy. ${ }^{4,5}$ A colonoscopy procedure should be performed within a reasonable time frame, as increased time to colonoscopy causes anxiety in screening participants with a positive test and is associated with a poorer prognosis. $^{4,6,7}$

In tax-funded national screening programs, adherence to diagnostic colonoscopy is generally high ${ }^{8,9}$ compared $^{-}$ to $\mathrm{CRC}$ screening in individual and insurance-financed programs. ${ }^{5,10}$ The Danish Colorectal Cancer Screening Program was initiated in 2014, and in the first 3 years of the screening program, adherence to diagnostic colonoscopy was $88 \%-90 \%$ within 2 months of a positive iFOBT. ${ }^{31}$ Still, this leaves one out of 10 people with a positive screening test but unconfirmed CRC status.

Studies of other universally offered CRC screening programs using FOBT have identified lower adherence to diagnostic colonoscopy among people living far away from a regional capital, ${ }^{11}$ in deprived areas, ${ }^{9,12,13}$ or in neighborhoods with many non-whites or many people with poor self-reported health. ${ }^{9}$ As part of a large Danish randomized controlled trial $(\mathrm{N}=30,967)$ initiated in 1985, Jørgensen et al asked 93 non-adherers among 1,559 persons with a positive guaiac fecal occult blood test to state why they refused the diagnostic colonoscopy. More than $40 \%$ could not provide a specific reason, $25 \%$ had severe comorbidity, and the remaining individuals reported either bleeding hemorrhoids or fissures, a former CRC diagnosis, or that they felt free of disease. ${ }^{14}$ Severe comorbidity may be a contraindication for undergoing a colonoscopy procedure or otherwise cause barriers for adherence to diagnostic colonoscopy. Therefore, we aimed to evaluate comorbidity and demographic factors (age, gender, and region of living) as predictors of adherence to diagnostic colonoscopy after a positive iFOBT in the Danish
Colorectal Cancer Screening Program in order to identify and characterize groups with low adherence.

\section{Materials and methods}

\section{The Danish Colorectal Cancer Screening Program}

The Danish health care system is predominantly tax funded, and five administrative regions own the public hospitals and run the CRC screening program in a standardized way. CRC screening is offered free of charge to all residents between 50 and 74 years of age. Invitations are mailed by post and include an iFOBT kit with a prepaid return envelope. The invitation letter states that individuals in a surveillance program for CRC should not participate in the iFOBT screening and that individuals with Crohn's disease or ulcerative colitis should discuss relevancy of screening with their general practitioner.

The CRC screening program was initiated on March 1, 2014 , and the first screening round lasted until the end of 2017, followed by biennial screening. In the first round, the target population was invited according to a random sequence of birth months, although individuals who turned 50 or 75 within the first round, received their first invitation no later than the month of that particular birthday, as they were entering or leaving the target population on that birthday. ${ }^{15}$ As the remaining individuals were invited randomly, the 50 -year olds and especially the 75-year olds were overrepresented in the beginning of the first screening round because they had not been invited before.

In case of a positive iFOBT, a diagnostic colonoscopy was booked at a colonoscopy unit and a letter was automatically sent directly to the participant. A national CRC screening guideline specifies two written reminders and, if necessary, follow-up by a telephone call to ensure comprehension of the invitation. ${ }^{16}$

\section{Study population}

In this cross-sectional study, we included individuals invited in the first 6 months (March 1, 2014, to August 31, 2014) of the CRC screening program $(\mathrm{N}=195,999)$, who received a positive iFOBT result before November 30, 2014 ( $n=8,373$; Figure 1), ie, within 3-9 months from receiving the invitation. We excluded individuals who died before a diagnostic colonoscopy could be performed $(n=7)$ and individuals who had a colonoscopy within the past year before the positive screening test $(n=254)$, as they are not recommended to have a new colonoscopy. Thus, the final study population consisted of 8,112 individuals. In all, 137 individuals had Crohn's disease or ulcerative colitis, but we chose not to exclude these individuals from the primary analyses, as they were advised 


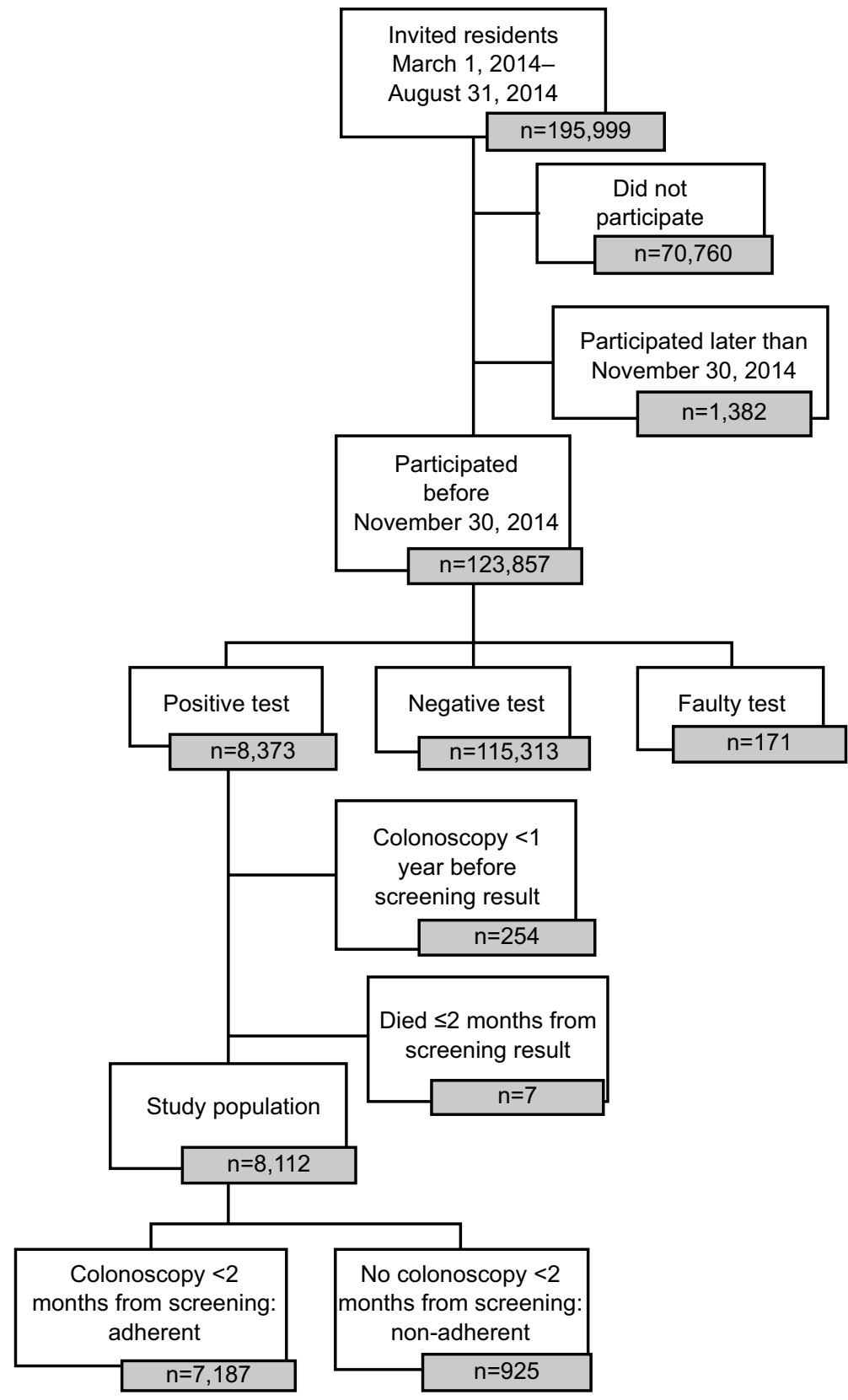

Figure I Flowchart of study population.

in the invitation letter to participate depending on advice from their doctors, and those who participated should receive a colonoscopy like the other participants. However, 16.8\% of the 137 patients were excluded as part of the group with a colonoscopy within the past year.

\section{Data and variables}

The study is based on registry data from the Danish Colorectal Cancer Screening Database (DCCSD) and the Danish National Patient Registry (DNPR), linked via the unique civil personal registration (CPR) number, assigned to all Danish residents. ${ }^{17}$ The DCCSD supplied data on gender, birthdate, invitation date, iFOBT result, colonoscopy procedures, and vital status of the study population. The DCCSD consists of data from existing registries (the regions' Invitation and Administration Module, the DNPR, and the Pathology Registry). Previously, we validated the DCCSD and found the data to be of acceptable quality for research purposes. ${ }^{15}$ The DNPR holds data on all somatic admissions to Danish hospitals since 1977. Outpatient contacts have been included since 1995. Variables in the DNPR include dates of admission and discharge, ICD-10 diagnosis codes, and procedures performed. ${ }^{18-20}$ These data were used to calculate comorbidity measures as described in the following. The study is included 
in the Danish Data Protection Agency data approval (j. no. 2015-57-0002) administered by Aarhus University (j. no. 2016-051-000001, 711).

\section{Study variables}

We assessed comorbidity using different measures: 1) the Charlson Comorbidity Index (CCI) score, ${ }^{21} 2$ ) single diagnoses from the CCI, and 3) the number of in-hospital stays within the past year.

CCI scores were calculated with a 10-year look-back period and split into three categories of total scores $(0,1-2$, and $\geq 3$ ). The CCI includes 19 chronic diseases (Score 1: myocardial infarction, congestive heart failure, peripheral vascular disease, cerebrovascular disease, dementia, chronic pulmonary disease, connective tissue disease, ulcer disease, mild liver disease, diabetes mellitus, and hemiplegia. Score 2: moderate/severe renal disease, diabetes mellitus with chronic complications, any tumor, leukemia, and lymphoma. Score 3: moderate/severe liver disease. Score 6: metastatic solid tumor and AIDS) that have been given weights reflecting the likelihood of 1-year mortality and thus the disease severity. ${ }^{21}$ We included CCI as the sum of a person's scores, and in separate analyses, we included the most prevalent single diseases and disease groups from the CCI. Thygesen et $\mathrm{al}^{22}$ validated the DNPR specifically for the calculation of CCI and found high positive predictive values (PPVs) for all the included diseases and an overall PPV of $98 \%$.

We calculated the number of in-hospital stays (irrespective of length and diagnosis) within the past year before positive iFOBT and categorized them as $0,1-2$, and $\geq 3$ stays. As the CCI calculation is based on hospital contacts, the CCI score and number of in-hospital stays are related. The simple count of in-hospital stays is a broader measure, as it includes all diseases and captures recent use for any reason.

Age was obtained at the time of a positive test, and therefore, some individuals were older than the target population of 50-74 years, as their participation surpassed their 75 th birthday. Age was categorized in five-year groups ( $<55$ years, 55-59 years, 60-64 years, 65-69 years, 70-74 years, and 75 years) but collapsed into three age groups for the regression analysis ( $<70$ years, 70-74 years, and 75 years) after examining the functional form using restricted cubic splines regression. This showed a marked decrease in adherence after age of 70 years, which became larger by 75 years, and 70 and 75 years were therefore used for categorization. Region of residence was defined as the North Denmark Region, the Central Denmark Region, the Region of Southern Denmark, the Capital Region of Denmark, and the Zealand Region.
We defined adherence to diagnostic colonoscopy as a colonoscopy performed within 2 months of a positive screening test, identical to the adherence definition of the DCCSD. ${ }^{23}$ Colonoscopy was defined by the ICD-10 code for a colonoscopy (KUJF32 or KUJF35) or colonography (UXCD80), which is used in cases of difficult passage of the colon. Our previous validation of the $\mathrm{DCCSD}^{15}$ showed some incompleteness in the registration of these codes. Thus, in the present study, we therefore also used supplementary codes, describing aspects of the colonoscopy procedure (ZPY1A, ZPY1B, ZPY1C, ZPY1D, ZPY1E, KJFA15, KJFA55, KJGA05, KJGA52) to identify performed colonoscopies.

\section{Statistics}

We calculated proportions to describe characteristics of the study population. Adherence was calculated as the proportion of individuals who underwent a diagnostic colonoscopy of all individuals with a positive iFOBT. We evaluated the crude association between the potential predictors and diagnostic colonoscopy adherence (yes vs no) in binomial regression models and calculated prevalence proportion differences (PPDs) with 95\% confidence interval (CI). In addition, we ran adjusted models in which the predictors were mutually adjusted for. Furthermore, we stratified on gender and age ( $<70$ years vs $\geq 70$ years), as these factors may modify associations between comorbidity and adherence.

In a sensitivity analysis, we altered the definition of adherence to include a diagnostic colonoscopy procedure performed within 3 months instead of only 2 months after a positive iFOBT. In another sensitivity analysis, we excluded individuals with inflammatory bowel disease, as some of them should not participate in CRC screening because of existing programs.

We allowed all individuals to have a minimum of 3 months of response time from date of invitation to date of stool sample analysis. However, the minimum response time varied from 3 to 9 months, depending on the date of invitation. The timeliness in which an individual submits the sample might be related both to comorbidity and demography and to the timeliness in which that individual receives a diagnostic colonoscopy. This could create a spurious association between comorbidity and adherence. Hence, the time from invitation to participation ("response time") was included in adjusted models.

\section{Supplementary analysis of hospital charts}

To further unfold reasons for nonadherence to diagnostic colonoscopy, we conducted a supplementary analysis of hospital charts. We did not have the resources to review 
hospital charts of all individuals who were considered nonadherent in our study, and therefore, we chose the region with the lowest adherence (the Capital Region) to ensure maximum identification of reasons for not receiving a colonoscopy. Hospital charts of all non-adherent individuals from the Capital Region of Denmark were examined for documented reasons for not undergoing a diagnostic colonoscopy. We categorized these reasons and calculated prevalence proportions with $95 \%$ CIs. Categories included "colonoscopy within 18 months before positive iFOBT", "colonoscopy later than two months after positive iFOBT, or in private practice", "in surveillance program for inflammatory bowel disease or other risk factors", "benign comorbidity prevents further diagnostics", "malignant comorbidity prevents further diagnostics", "the participant wanted no further diagnostic work-up", "deceased before diagnostics", and "unable to contact patient or other/ unknown".

\section{Results}

Overall, adherence to diagnostic colonoscopy was $88.6 \%$ among the 8,112 individuals in the study population (Table 1). We found the highest adherence among men, individu- als younger than 55 years, residents of the North Denmark Region, people with a CCI score of 0 , and people with no in-hospital stays. Adherence was $\sim 90 \%$ across age groups but dropped to $83.8 \%$ among the oldest participants $(75$ years). The target population for CRC screening was people aged 50-74 years, but as some responded to their invitation after their 75 th birthday, $18.5 \%$ were 75 years old. This age group was overrepresented due to the invitation procedure.

Adherence dropped from $90.3 \%$ in people with a CCI score of 0 to $79.9 \%$ in those with a score of $\geq 3$. For individuals with 0 and $\geq 3$ in-hospital stays, adherence was $89.5 \%$ and $73.6 \%$, respectively.

In total, $34.9 \%$ of the study population had at least one of the 19 diseases in the CCI. The most prevalent diseases were any tumor $(9.6 \%)$, chronic pulmonary disease $(7.4 \%)$, cerebrovascular disease (6.5\%), and diabetes I+II (6.2\%).

Comorbidity was inversely associated with adherence to diagnostic colonoscopy (Table 2); compared with a CCI score of 0 , the adjusted PPDs and 95\% CIs were -2.30 (95\% CI: $-3.87 ;-0.74$ ) for a CCI score of $1-2$ and -9.24 (95\% CI: $-12.30 ;-6.19)$ for a CCI score of $\geq 3$. Older age was associated with a lower adherence; adjusted PPD for 75 years was $-4.20(95 \% \mathrm{CI}:-6.19 ;-2.20)$ compared with that

Table I Characteristics of the study population overall and by adherence and nonadherence to diagnostic colonoscopy ( $\mathrm{n}=8, \mathrm{I}$ I2)

\begin{tabular}{|c|c|c|c|c|}
\hline Characteristics & All, $n$ & $\begin{array}{l}\text { Adherence proportion, } \\
\text { row } \%\end{array}$ & $\begin{array}{l}\text { Adherent }(n=7,187) \text {, } \\
\%\end{array}$ & $\begin{array}{l}\text { Non-adherent } \\
(n=925), \%\end{array}$ \\
\hline \multicolumn{5}{|l|}{ Gender } \\
\hline Women & 3,627 & 88.3 & 44.6 & 45.7 \\
\hline Men & 4,485 & 88.8 & 55.4 & 54.3 \\
\hline \multicolumn{5}{|l|}{ Age, years } \\
\hline$<55$ & 1,935 & 90.4 & 24.3 & 20.0 \\
\hline $55-59$ & 702 & 89.7 & 8.8 & 7.8 \\
\hline $60-64$ & 945 & 89.8 & 11.8 & 10.4 \\
\hline $65-69$ & 1,476 & 89.4 & 18.4 & 16.9 \\
\hline $70-74$ & $1,55 \mid$ & 88.9 & 19.2 & 18.7 \\
\hline 75 & $\mathrm{I}, 503$ & 83.8 & 17.5 & 26.3 \\
\hline \multicolumn{5}{|l|}{ Region of residence } \\
\hline North Denmark Region & 1,035 & 92.5 & 13.3 & 8.4 \\
\hline Central Denmark Region & 1,960 & 91.6 & 25.0 & 17.8 \\
\hline Region of Southern Denmark & 2,067 & 90.2 & 25.9 & 21.8 \\
\hline Capital Region of Denmark & $2,|3|$ & 82.6 & 24.5 & 40.0 \\
\hline Zealand Region & 919 & 88.0 & 11.3 & 11.9 \\
\hline \multicolumn{5}{|l|}{$\mathrm{CCl}$ score } \\
\hline 0 & 5,283 & 90.3 & 66.4 & 55.4 \\
\hline $\mathrm{I}-2$ & 2,137 & 87.2 & 25.9 & 29.6 \\
\hline$\geq 3$ & 692 & 79.9 & 7.7 & 15.0 \\
\hline \multicolumn{5}{|l|}{ In-hospital stays ${ }^{a}$} \\
\hline 0 & 6,722 & 89.5 & 83.7 & 76.2 \\
\hline $\mathrm{I}-2$ & $\mathrm{I}, \mathrm{I} 70$ & 86.2 & 14.0 & 17.5 \\
\hline$\geq 3$ & 220 & 73.6 & 2.3 & 6.3 \\
\hline
\end{tabular}

Note: ${ }^{a}$ Number of in-hospital stays within the last year preceding the positive screening test result.

Abbreviation: $\mathrm{CCl}$, Charlson Comorbidity Index. 
for $<70$ years. We found similar adherence when comparing men and women.

The results show variation in adherence between participants living in different regions. Adherence was highest in the North Denmark Region and lowest in the Capital Region of Denmark (adjusted PPD $=-8.22$, 95\% CI: $-10.50 ;-5.97)$.

In the evaluation of individual diseases as predictors of adherence, the adjusted PPDs ranged from -6.64 to -1.57 for cardiovascular disease, chronic pulmonary disease, diabetes, and cancer compared with no disease, thus indicating reduced adherence. Compared with no in-hospital stays, the adjusted
PPDs were $-2.41(95 \% \mathrm{CI}:-4.43 ;-0.39)$ for one to two stays and -14.50 (95\% CI: $-20.30 ;-8.74)$ for $\geq 3$ stays (Table 2$)$.

A stratified analysis showed that the association between comorbidity and adherence to diagnostic colonoscopy varied by age for women (Table 3 ). For women $<70$ years, the adjusted PPDs compared to that for no comorbidity were $1.56(95 \% \mathrm{CI}:-1.17 ; 4.28)$ for CCI score $1-2$ and -12.7 (95\% CI: $-20.90 ;-4.40)$ for CCI score $\geq 3$. For women aged 70-74 years, adherence was similar across comorbidity categories. However, for women aged 75 years, PPDs were -5.18 and -18.9 for CCI scores $1-2$ and $\geq 3$ compared to 0 , respectively.

Table 2 PPDs with $95 \%$ Cls for predictors of adherence to diagnostic colonoscopy

\begin{tabular}{|c|c|c|c|c|}
\hline & \multicolumn{2}{|c|}{ Unadjusted } & \multicolumn{2}{|c|}{ Adjusted $^{\mathrm{a}, \mathrm{b}}$} \\
\hline & PPD & $95 \% \mathrm{Cl}$ & PPD & $95 \% \mathrm{Cl}$ \\
\hline \multicolumn{5}{|l|}{ Gender } \\
\hline Women & 0.00 & - & 0.00 & - \\
\hline Men & 0.47 & $-0.92 ; 1.86$ & 1.07 & $-0.23 ; 2.37$ \\
\hline \multicolumn{5}{|l|}{ Age, years } \\
\hline$<70$ & 0.00 & - & 0.00 & - \\
\hline $70-74$ & -1.09 & $-2.86 ; 0.68$ & -1.24 & $-2.96 ; 0.47$ \\
\hline 75 & -6.10 & $-8.14 ;-4.07$ & -4.20 & $-6.19 ;-2.20$ \\
\hline \multicolumn{5}{|l|}{ Region of residence } \\
\hline North Denmark Region & 0.00 & - & 0.00 & - \\
\hline Central Denmark Region & -0.88 & $-2.91 ; 1.14$ & -0.31 & $-2.27 ; 1.66$ \\
\hline Region of Southern Denmark & -2.24 & $-4.29 ;-0.18$ & -1.08 & $-3.07 ; 0.90$ \\
\hline Capital Region of Denmark & -9.83 & $-12.10 ;-7.55$ & -8.22 & $-10.50 ;-5.97$ \\
\hline Zealand Region & -4.43 & $-7.08 ;-1.79$ & -2.70 & $-5.28 ;-0.12$ \\
\hline \multicolumn{5}{|l|}{ CCl score } \\
\hline 0 & 0.00 & - & 0.00 & - \\
\hline $\mathrm{I}-2$ & -3.13 & $-4.76 ;-1.50$ & -2.30 & $-3.87 ;-0.74$ \\
\hline$\geq 3$ & -10.40 & $-13.50 ;-7.31$ & -9.24 & $-12.30 ;-6.19$ \\
\hline \multicolumn{5}{|l|}{ Cardiovascular disease $^{a}$} \\
\hline No & 0.00 & - & 0 & - \\
\hline Yes & -7.68 & $-10.00 ;-5.37$ & -6.64 & $-8.91 ;-4.36$ \\
\hline \multicolumn{5}{|l|}{ Chronic pulmonary disease } \\
\hline No & 0.00 & - & 0.00 & - \\
\hline Yes & -6.35 & $-9.46 ;-3.23$ & -5.42 & $-8.48 ;-2.37$ \\
\hline \multicolumn{5}{|l|}{ Diabetes $^{b}$} \\
\hline No & 0 & - & 0 & - \\
\hline Yes & -5.14 & $-8.28 ;-1.99$ & -4.68 & $-7.74 ;-1.62$ \\
\hline \multicolumn{5}{|l|}{ Cancer ${ }^{c}$} \\
\hline No & 0.00 & - & 0.00 & - \\
\hline Yes & -2.57 & $-5.05 ;-0.10$ & -1.57 & $-3.96 ; 0.83$ \\
\hline \multicolumn{5}{|l|}{ In-hospital stays ${ }^{d}$} \\
\hline 0 & 0.00 & - & 0.00 & - \\
\hline $1-2$ & -3.36 & $-5.47 ;-1.25$ & -2.41 & $-4.43 ;-0.39$ \\
\hline$\geq 3$ & -15.90 & $-21.70 ;-10.00$ & -14.50 & $-20.30 ;-8.74$ \\
\hline
\end{tabular}

Notes: "Includes "myocardial infarction", “congestive heart failure”, “peripheral vascular disease”, and "cerebrovascular disease”. 'Includes "diabetes I+II" and "diabetes with end organ damage". Includes "any tumor", "leukemia", and "metastatic solid tumor". "Number of in-hospital stays within the last year preceding the positive screening test result. eln the model of the association between adherence to diagnostic colonoscopy and gender, age, region, and CCl, these are mutually adjusted for each other, in addition to response time. 'The models of the association between adherence to diagnostic colonoscopy and cardiovascular disease, chronic pulmonary disease, diabetes, cancer and in-hospital stays, respectively, are adjusted for gender, age group, region of residence, and response time.

Abbreviations: PPD, prevalence proportion difference; Cl, confidence interval; $\mathrm{CCl}$, Charlson Comorbidity Index. 
For men, the association between comorbidity and adherence was relatively similar across age groups. However, the PPD of CCI score $\geq 3$ compared to 0 was highest in the youngest age group ( $\mathrm{PPD}=-10.2,95 \% \mathrm{CI}:-15.90 ;-4.39$ ).

The sensitivity analysis allowing 3 months from a positive iFOBT to a diagnostic colonoscopy increased overall adherence from $88.6 \%$ to $90.1 \%$, and the adjusted PPDs decreased except for the age group 70-74 years. Most notably, the PPDs for age 75 years compared to age $<70$ years and CCI score $\geq 3$ compared to CCI score 0 changed to -4.41 (95\% CI:-6.32; -2.50) and -8.51 (95\% CI:-11.40;-5.58), respectively. Regional variation also diminished (adjusted PPDs ranged from -0.06 to -6.39 compared to -0.88 to -9.83 in the main analysis).

Furthermore, 114 individuals had received a diagnosis of Crohn's disease or ulcerative colitis within 10 years prior to the positive iFOBT, and adherence to colonoscopy in this group was $70.2 \%$. When excluding these individuals in a sensitivity analysis, the overall adherence changed from $88.60 \%$ to $88.86 \%$, and the change in effect estimates was negligible.
The distribution of reasons for nonadherence, obtained via the supplementary analysis of hospital charts from nonadherent persons in the Capital Region, is shown in Table 4. The most prevalent reason for nonadherence was participants' decision not to have further diagnostic work-up (38\%), while $7 \%$ of the non-adherent individuals had a benign or malignant comorbidity that prevented further diagnostics. In comparison, $35.8 \%$ of the non-adherent individuals from the Capital Region had a CCI score of 1 or more in the main analysis.

Another $30.8 \%$ had a diagnostic colonoscopy performed in private practice or later than 2 months after the date of the positive test, which we used as the cutoff value in the definition of adherence.

\section{Discussion}

In our study, overall adherence to diagnostic colonoscopy within 2 months after a positive iFOBT was $88.6 \%$. This is comparable to other European CRC screening programs, which have reported adherence proportions ranging from $81.5 \%$ in a pilot program in the UK ${ }^{24}$ to $92.4 \%$ in the Swedish population-based program. ${ }^{25}$ The $88.6 \%$ adherence is

Table 3 PPDs with 95\% Cls for adherence to diagnostic colonoscopy for men and women by $\mathrm{CCl}$ score and stratified by age

\begin{tabular}{|c|c|c|c|c|c|c|}
\hline & \multicolumn{2}{|c|}{$<70$ years, $n=5,058$} & \multicolumn{2}{|c|}{ 70-74 years, $n=I, 55 I$} & \multicolumn{2}{|c|}{75 years, $n=I, 503$} \\
\hline & PPD $^{\mathrm{a}}$ & $95 \% \mathrm{Cl}$ & PPD $^{\mathrm{a}}$ & $95 \% \mathrm{Cl}$ & PPD $^{a}$ & $95 \% \mathrm{Cl}$ \\
\hline \multicolumn{7}{|l|}{ Women } \\
\hline $\mathrm{CCl}$ score 0 & 0.00 & - & 0.00 & - & 0.00 & - \\
\hline $\mathrm{CCl}$ score $\mathrm{I}-2$ & 1.56 & $-I .17 ; 4.28$ & -0.46 & $-5.48 ; 4.55$ & -5.18 & $-10.30 ;-0.06$ \\
\hline $\mathrm{CCl}$ score $\geq 3$ & -12.7 & $-20.90 ;-4.40$ & -0.94 & $-8.56 ; 6.67$ & -18.9 & $-29.50 ;-8.26$ \\
\hline \multicolumn{7}{|l|}{ Men } \\
\hline $\mathrm{CCl}$ score 0 & 0.00 & - & 0.00 & - & 0.00 & - \\
\hline $\mathrm{CCl}$ score $\mathrm{I}-2$ & -2.68 & $-5.29 ;-0.08$ & -6.42 & $-10.80 ;-1.98$ & -4.26 & $-9.64 ; 1.12$ \\
\hline $\mathrm{CCl}$ score $\geq 3$ & -10.2 & $-15.90 ;-4.39$ & -9.40 & $-16.20 ;-2.60$ & -6.6 & $-14.00 ; 0.78$ \\
\hline
\end{tabular}

Note: adjusted for region of residence and response time.

Abbreviations: PPD, prevalence proportion difference; $\mathrm{Cl}$, confidence interval; $\mathrm{CCl}$, Charlson Comorbidity Index.

Table 4 Reasons for no diagnostic colonoscopy among 370 individuals, as recorded in hospital records in the Capital Region of Denmark

\begin{tabular}{|c|c|c|c|}
\hline & $\mathbf{n}$ & Proportion, \% & $95 \% \mathrm{Cl}$ \\
\hline The participant wanted no further diagnostic work-up & 142 & 38.4 & $33.4 ; 43.5$ \\
\hline $\begin{array}{l}\text { Colonoscopy later than } 2 \text { months after positive iFOBT or in private practice not yet } \\
\text { reported to the DNPR }\end{array}$ & 114 & 30.8 & $26.1 ; 35.8$ \\
\hline Unable to contact patient or other/unknown & 46 & 12.4 & $9.2 ; 16.2$ \\
\hline In surveillance program for inflammatory bowel disease or other risk factors & 21 & 5.7 & $3.5 ; 8.5$ \\
\hline Benign comorbidity prevents further diagnostics & 19 & 5.1 & $3.1 ; 7.9$ \\
\hline Colonoscopy within 18 months before positive iFOBT & 17 & 4.6 & $2.2 ; 6.0$ \\
\hline Malignant comorbidity prevents further diagnostics & 7 & 1.9 & $0.8 ; 3.9$ \\
\hline Deceased before diagnostics & 4 & I.I & $0.3 ; 2.7$ \\
\hline
\end{tabular}

Abbreviations: $\mathrm{Cl}$, confidence interval; iFOBT, immunochemical Fecal Occult Blood Test; DNPR, Danish National Patient Registry. 
below the desirable level of $90 \%$ adherence suggested by the European Commission but above the recommended quality standard of $85 \%{ }^{4}$

We found that age of 75 years, region of residence, a CCI score of 1 or more, and one or more in-hospital stays within the last year were predictors of nonadherence. For the specific diseases, having a cancer diagnosis was only weakly associated with nonadherence, whereas cardiovascular disease, chronic pulmonary disease, and diabetes were strong predictors of nonadherence. This may be explained by a high awareness of CRC screening among individuals with an existing or prior cancer diagnosis.

Overall adherence increased in the sensitivity analysis, allowing 3 months from a positive iFOBT to a diagnostic colonoscopy. However, diagnostic colonoscopy should be performed within short time after screening, that is, within 31 days according to the European guidelines ${ }^{4}$ and within 14 days according to the Danish diagnostic evaluation guarantee. ${ }^{16}$ Furthermore, a colonoscopy performed, eg, 6 months after a positive iFOBT may be triggered by symptoms developed in the meantime, in which case it is not strictly a screening-related diagnostic colonoscopy.

The considerable difference in adherence depending on region of residence persisted after adjustment for gender and age but decreased in the sensitivity analysis. This may be explained by differences in capacity to provide the number of needed colonoscopies in a timely manner during the first period of the screening program, which is evident from the large number of patients reported not to be treated within the guaranteed "waiting time" 26,27 in the respective regions. ${ }^{28-30}$ Adherence to diagnostic colonoscopy is thereby not just adherence of the patient but also dependent on the health care system's capacity to provide colonoscopies in due time. However, overall adherence to diagnostic colonoscopy has been stable since the introduction of screening in 2014. ${ }^{31}$

An American Veterans Health Administration study from 2011 found no association between comorbidity and adherence to follow-up colonoscopy. However, they defined adherence as receiving a colonoscopy within a whole year after screening. ${ }^{32}$ Two, more recent, American studies of CRC screening found lower adherence with increasing comorbidity and age, which is in line with our results. However, overall adherence was low (50\% within 6 months and $17.0 \%-61.9 \%$ within 2 months, respectively) in these American studies. ${ }^{33,34}$ Thus, comorbidity and age seem to be predictors of adherence to diagnostic colonoscopy after a positive FOBT, both in screening programs with low and high overall adherence.
The supplementary analysis of hospital charts from the Capital Region of Denmark revealed that in only $7 \%$ of the non-adherent patients, the direct reason for no diagnostic colonoscopy was underlying benign or malignant comorbidity. Hence, it seems that only a small part of the association between comorbidity and adherence is due to physical inability to undergo a diagnostic colonoscopy.

The main methodological strength of this study is the use of nationwide registry data, which were collected independently of this study, thus minimizing the risk of selection and information biases. This enabled us to include the complete population of screening participants with a positive iFOBT.

A limitation of our study is the lack of data on potential predictors such as education, income, and psychiatric morbidity. Social inequality in morbidity ${ }^{37}$ means that socioeconomic factors may explain some of the association between comorbidity and adherence to diagnostic colonoscopy. Two studies of the Danish CRC screening program found socioeconomic inequality in iFOBT participation, ${ }^{38,39}$ and a study of the British program found lower adherence to diagnostic colonoscopy in people living in deprived areas. ${ }^{9}$ Likewise, a study on the CRC screening program in the Basque region of Spain found associations between area deprivation score and both screening participation and adherence to diagnostic colonoscopy. ${ }^{40}$ However, the associations were reverse. Thus, participation in the screening program and adherence to diagnostic colonoscopy were lowest in individuals from the least deprived areas. The authors state that this may not be explained by high socioeconomic status but by higher utilization of private clinics not reporting to their study.

Even though adherence to diagnostic colonoscopy in the Danish CRC screening program is high, improvements may still be warranted. IFOBT screening has no effect in people who are tested positive but do not attend the subsequent diagnostic colonoscopy, and it may even do harm. As we found that especially individuals with comorbidity were less likely to receive a colonoscopy, additional support for this group of screening participants may be needed. In contrast, some terminally ill patients are simply too sick to have a colonoscopy. However, people live with chronic diseases such as diabetes, cardiovascular disease, and pulmonary disease for many years, and this should therefore not keep them from having a colonoscopy, and full potential effect of the screening program.

Selby et al reviewed studies of interventions to improve adherence to diagnostic colonoscopy following a positive FOBT screening. Many of these factors (phone contact in addition to mailing of test result and colonoscopy appointment and performance feedback to colonoscopy providers) are already implemented in the Danish CRC screening 
program. However, different models of pre-colonoscopy assessment or use of patient navigators could be directed toward addressing patients' barriers or concerns about the colonoscopy procedure. ${ }^{41}$

\section{Conclusion}

This population-based study evaluated demographic and comorbidity predictors of adherence to diagnostic colonoscopy in an iFOBT-based CRC screening program. Even though adherence to diagnostic colonoscopy after a positive iFOBT is high $(88.6 \%)$ in the Danish program, some individuals are lost in the process. We found that older age, a CCI score of one or more, cardiovascular disease, chronic pulmonary disease, diabetes, and one or more in-hospital stays within the last year were associated with nonadherence to diagnostic colonoscopy.

\section{Acknowledgments}

The following members of the DCCSD steering group have contributed to the establishment of the DCCSD and have supported this study: Dorte Linnemann, Department of Pathology, Herlev and Gentofte Hospital, Herlev; Berit Andersen, Department of Public Health Programs, Randers Regional Hospital, Randers; Gunnar Baatrup, Department of Surgery, Odense University Hospital, and Department of Clinical Science, University of Southern Denmark, Odense; Lennart Jan Friis-Hansen, Center for Genomic Medicine, Rigshospitalet, and University of Copenhagen, Copenhagen; Jens Christian Riis Jørgensen, Department of Colorectal Cancer Surgery, Vejle Hospital, Vejle; Mona Skarbye, Department of Gastrointestinal Surgery, Regional Hospital Slagelse, Slagelse; Per Gandrup, Department of Surgery A, Aalborg University Hospital, Aalborg; Henrik Nørgaard, Danish Radiology Society; Per Ejstrud, Danish Society for Gastroenterology and Hepatology.

\section{Disclosure}

The authors report no conflicts of interest in this work.

\section{References}

1. GLOBOCAN. Colorectal Cancer Estimated Incidence, Mortality and Prevalence Worldwide in 2012. Available from: http://globocan.iarc.fr/ Pages/fact_sheets_cancer.aspx?cancer=colorectal. Accessed 13th March 2015.

2. Garborg K, Holme Ø, Løberg M, Kalager M, Adami HO, Bretthauer M. Current status of screening for colorectal cancer. Ann Oncol. 2013;24(8):1963-1972.

3. Hewitson P, Glasziou P, Watson E, Towler B, Irwig L. Cochrane systematic review of colorectal cancer screening using the fecal occult blood test (hemoccult): an update. Am J Gastroenterol. 2008;103(6):1541-1549.
4. Directorate-General for Health and Consumers (European Commission), Executive Agency for Health and Consumers, World Health Organization. European Guidelines for Quality Assurance in Colorectal Cancer Screening and Diagnosis. Segnan N, Patnick J, von Karsa L, editors. Luxembourg: Publications Office of the European Union; 2010.

5. Etzioni DA, Yano EM, Rubenstein LV, et al. Measuring the quality of colorectal cancer screening: the importance of follow-up. Dis Colon Rectum. 2006;49(7):1002-1010.

6. Meester RG, Zauber AG, Doubeni CA, et al. Consequences of increasing time to colonoscopy examination after positive result from fecal colorectal cancer screening test. Clin Gastroenterol Hepatol. 2016;14(10):1445-1451.e8.

7. Corley DA, Jensen CD, Quinn VP, et al. Association between time to colonoscopy after a positive fecal test result and risk of colorectal cancer and cancer stage at diagnosis. JAMA. 2017;317(16):1631-1641.

8. Blom J, Kilpeläinen S, Hultcrantz R, Törnberg S. Five-year experience of organized colorectal cancer screening in a Swedish population increased compliance with age, female gender, and subsequent screening round. J. Med. Screen. 2014;21(3):144-150.

9. Morris S, Baio G, Kendall E, et al. Socioeconomic variation in uptake of colonoscopy following a positive faecal occult blood test result: a retrospective analysis of the NHS Bowel Cancer Screening Programme. Br J Cancer. 2012;107(5):765-771.

10. Liss DT, Brown T, Lee JY, et al. Diagnostic colonoscopy following a positive fecal occult blood test in community health center patients. Cancer Causes Control. 2016;27(7):881-887.

11. Dupont-Lucas C, Dejardin O, Dancourt V, Launay L, Launoy G, Guittet L. Socio-geographical determinants of colonoscopy uptake after faecal occult blood test. Dig Liver Dis. 2011;43(9):714-720.

12. Ferrat E, Le Breton J, Veerabudun K, et al. Colorectal cancer screening: factors associated with colonoscopy after a positive faecal occult blood test. Br J Cancer. 2013;109(6):1437-1444.

13. Mansouri D, McMillan DC, Grant Y, Crighton EM, Horgan PG. The impact of age, sex and socioeconomic deprivation on outcomes in a colorectal cancer screening programme. PLoS One. 2013;8(6):e66063.

14. Jørgensen OD, Kronborg O, Fenger C. A randomised study of screening for colorectal cancer using faecal occult blood testing: results after 13 years and seven biennial screening rounds. Gut. 2002;50(1):29-32.

15. Thomsen MK, Njor SH, Rasmussen M, et al. Validity of data in the Danish Colorectal Cancer Screening Database. Clin Epidemiol. 2017;9:105-111.

16. Tværregional koordinationsgruppe for tarmkræftscreening. Manual for implementering og drift af tvaerregional tarmkraeftscreening version 3. [Cross-regional coordination group for colorectal cancer screening. 2017. Manual for implementation and running of cross-regional colorectal cancer screening version 3]; 2017. Available from: http:// www.regionshospitalet-randers.dk/siteassets/afdelinger/afdeling-forfolkeundersogelser/pdf-episerver/retningslinjer/2017_03_10-manualfor-drift-af-tvarregional-tarmkraftscreening---version-3.pdf. Accessed November 5, 2018. Danish.

17. Schmidt M, Pedersen L, Sørensen HT. The Danish Civil Registration System as a tool in epidemiology. Eur J Epidemiol. 2014;29(8):541-549.

18. Andersen TF, Madsen M, Jørgensen J, Mellemkjoer L, Olsen JH. The Danish National Hospital Register. A valuable source of data for modern health sciences. Dan Med Bull. 1999;46(3):263-268.

19. Lynge E, Sandegaard JL, Rebolj M. The Danish national patient register. Scand J Public Health. 2011;39(7 Suppl):30-33.

20. Schmidt M, Schmidt SA, Sandegaard JL, Ehrenstein V, Pedersen L, Sørensen HT. The Danish National Patient Registry: a review of content, data quality, and research potential. Clin Epidemiol. 2015;7:449-490.

21. Charlson ME, Pompei P, Ales KL, MacKenzie CR. A new method of classifying prognostic comorbidity in longitudinal studies: development and validation. J Chronic Dis. 1987;40(5):373-383.

22. Thygesen SK, Christiansen CF, Christensen S, Lash TL, Sørensen HT. The predictive value of ICD-10 diagnostic coding used to assess Charlson comorbidity index conditions in the population-based Danish National Registry of Patients. BMC Med Res Methodol. 2011;11:83. 
23. Steering group for the Danish Colorectal Cancer Screening database, Competence Center for epidemiology and biostatistics North. Dansk tarmkræftscreeningsdatabase Pilotrapport 2014 [Danish Colorectal Cancer Screening Database pilot report 2014]; 2015. Available from: https://www.sundhed.dk/content/cms/45/61245_tarmkr\%C3\%A6ft. pdf. Accessed November 5, 2018. Danish.

24. UK Colorectal Cancer Screening Pilot Group. Results of the first round of a demonstration pilot of screening for colorectal cancer in the United Kingdom. BMJ 2004;329:133.

25. Blom J, Kilpeläinen S, Hultcrantz R, Törnberg S. Five-year experience of organized colorectal cancer screening in a Swedish population - increased compliance with age, female gender, and subsequent screening round. J Med Screen. 2014;21(3):144-150.

26. Ministry of Health. BEK nr 1749 af 21/12/2006 Historisk. Bekendtgørelse om behandling af patienter med livstruende kræftsygdomme m.v. - retsinformation.dk. [BEK no 1749 of 21/12/2006 historical. Consolidation Act of treatment of patients with life threatening cancer diseases]; 2005. Available from: https://www.retsinformation.dk/eli/ 1ta/2015/584. Accessed November 5, 2018. Danish.

27. Probst HB, Hussain ZB, Andersen O. Cancer patient pathways in Denmark as a joint effort between bureaucrats, health professionals and politicians--a national Danish project. Health Policy. 2012;105(1):65-70.

28. Sundhedsstyrelsen Maksimale ventetider for kræft og hjertesygdomme april 2014 [National Board of Health. Maximum waiting times for cancer and heart diseases April 2014]. Available from: https://sundhedsstyrelsen.dk/da/nyheder/2014/maksimale-ventetider-for-kraeftog-hjertesygdomme-april-2014. Accessed May 31, 2015. Danish.

29. Sundhedsstyrelsen. Maksimale ventetider for patienter med kræft- og hjertesygdomme maj 2014 [National Board of Health. Maximum waiting times for cancer and heart diseases May 2014]; 2014. Available from: https:// sundhedsstyrelsen.dk/da/nyheder/2014/maksimale-ventetider-for-patientermed-kraeft-og-hjertesygdomme-maj-2014. Accessed May 31, 2015.

30. Sundhedsstyrelsen. Maksimale ventetider: 204 overskridelser i juni 2014 (opdateret); [National Board of Health. Maximum waiting times: 204 exceedances in June 2014 (updated)] 2014. Available from: https://sundhedsstyrelsen.dk/da/nyheder/2014/maksimale-ventetider203-overskridelser-i-juni-2014. Accessed May 31, 2015.

31. Rasmussen M, Tybjerg J. Dansk tarmkraeftscreeningsdatabase Årsrapport 2016 Første 34 måneder af 1. nationale screeningsrunde Hvorfra udgår rapporten Kontaktperson for DTS i Regionernes Kliniske Kvalitetsudviklingsprogram (RKKP). [Danish Colorectal Cancer Screening Database yearly report First 34 months of 1st national screening round. Regional Clinical Qualitydevelopment Program]; 2017. Available from: $\mathrm{http}: / / \mathrm{www}$. regionshospitalet-randers.dk/siteassets/afdelinger/afdelingfor-folkeundersogelser/pdf-episerver/retningslinjer/20171221_dtsarsrapport-2016_offentlig-version.pdf. Accessed November 5, 2018. Danish.
32. Carlson CM, Kirby KA, Casadei MA, Partin MR, Kistler CE, Walter LC. Lack of follow-up after fecal occult blood testing in older adults: inappropriate screening or failure to follow up? Arch Intern Med. 2011;171(3):249-256.

33. Partin MR, Gravely AA, Burgess JF Jr, et al. Contribution of patient, physician, and environmental factors to demographic and health variation in colonoscopy follow-up for abnormal colorectal cancer screening test results. Cancer. 2017;123(18):3502-3512.

34. Chubak J, Garcia MP, Burnett-Hartman AN, et al; PROSPR consortium. Time to Colonoscopy after Positive Fecal Blood Test in Four U.S. Health Care Systems. Cancer Epidemiol Biomarkers Prev. 2016;25(2): 344-350.

35. Aalykke C. Koloskopiovervågning af patienter med kronisk inflammatorisk tarmsygdom (IBD) med henblik på udvikling af dysplasi og kolorektal cancer. [Colonoscopy monitoring of patients with chronic inflamatory bowel disease (IBD) for development of dysplasia and colorectal cancer]; 2014. Available from: https://www.dsgh.dk/images/ guidelines/pdfversion/ibdkrc_dsgh_guideline.pdf. Accessed November 5, 2018. Danish.

36. Vasen, Bülow; Leeds Castle Polyposis Group. Guidelines for the surveillance and management of familial adenomatous polyposis (FAP): a world wide survey among 41 registries. Colorectal Dis. 1999;1(4): 214-221.

37. M. Marmot, Friel, S., Bell, R., Houweling, TAJ, Taylor, S. On behalf of the Commission on Social Determinants of Health. Closing the gap in a generation: health equity through action on the social determinants of health. Final Report of the Commission on Social Determinants of Health. 2008.

38. Deding U, Henig AS, Salling A, Torp-Pedersen C, Bøggild H. Sociodemographic predictors of participation in colorectal cancer screening. Int J Colorectal Dis. 2017;32(8):1117-1124.

39. Larsen MB, Mikkelsen EM, Rasmussen M, et al. Sociodemographic characteristics of nonparticipants in the Danish colorectal cancer screening program: a nationwide cross-sectional study. Clin Epidemiol. 2017;9:345-354.

40. Hurtado JL, Bacigalupe A, Calvo M, et al. Social inequalities in a population based colorectal cancer screening programme in the Basque Country. BMC Public Health. 2015;15:1021.

41. Selby K, Baumgartner C, Levin TR, et al. Interventions to improve follow-up of positive results on fecal blood tests: a systematic review. Ann Intern Med. 2017;167(8):565-575.
Clinical Epidemiology

\section{Publish your work in this journal}

Clinical Epidemiology is an international, peer-reviewed, open access, online journal focusing on disease and drug epidemiology, identification of risk factors and screening procedures to develop optimal preventative initiatives and programs. Specific topics include: diagnosis, prognosis, treatment, screening, prevention, risk factor modification, Submit your manuscript here: https://www.dovepress.com/clinical-epidemiology-journa

\section{Dovepress}

systematic reviews, risk and safety of medical interventions, epidemiology and biostatistical methods, and evaluation of guidelines, translational medicine, health policies and economic evaluations. The manuscript management system is completely online and includes a very quick and fair peer-review system, which is all easy to use. 